\title{
Communication Network System for CAD of Functional Decomposition
}

\author{
E. Arai, K. Shirase, H. Wakamatsu \\ Dept. of Manufacturing Science, Graduate School of Eng., \\ Osaka University \\ 2-1 Yamadaoka, Suita, Osaka 565-0871, Japan \\ Tel: +81-6-6879-7555 \\ Fax: +81-6-6879-7570 \\ e-mail: arai@mapse.eng.osakau.ac.jp, \\ shirase@mapse.eng.osakau.ac.jp, \\ wakamatu@mapse.eng.osaka-u.ac.jp
}

\begin{abstract}
The present CAD/CAM systems transfer the geometric models of design objects mainly, and designers can not understand others' way of thinking with use of them. It is desired to transfer the designers' way of thinking via computer systems as well as design object descriptions. Design process starts in general by the input of the requirements/specifications. They are decomposed to the detailed ones. This paper deals with the communication network system among designers in the early conceptual design stage where the functional decomposition plays an important role.

Whenever each designer makes decisions to handle functions of designed objects, the communication network system looks for designers who may be affected on by the decisions automatically with use of the active database system, and help him/her to start communication.
\end{abstract}

\section{Keywords}

intelligent $\mathrm{CAD}$, functional decomposition, concurrent design, communication network, active database 


\section{INTRODUCTION}

Cooperative design is required in machine design, for decision making in the design process needs the different viewpoints. The present CAD/CAM systems transfer the geometric models of design objects mainly, and designers can not understand others' way of thinking with use of them. It is desired to transfer the designers' way of thinking via computer systems as well as design object descriptions. Design process starts in general by the input of the requirements/specifications. They are decomposed to the detailed ones (Tomiyama, 1993).

The design process is progressed by imagination, remembrance, reference, calculation and so on in the designers' heads. Designers may explain the reasons / ideas for decomposition, development, modelling, and other decisions, however, they are not clearly described in the CAD systems in spite of the importance and usefulness for designers to understand others' way of thinking that may affect their decision making (Arai, 1991).

\section{CAD OF FUNCTIONAL DECOMPOSITION}

CAD systems have to support designers to decompose the functional requirement of design solutions in the early stage of conceptual design. The architecture of such CAD systems is shown in Figure 1.

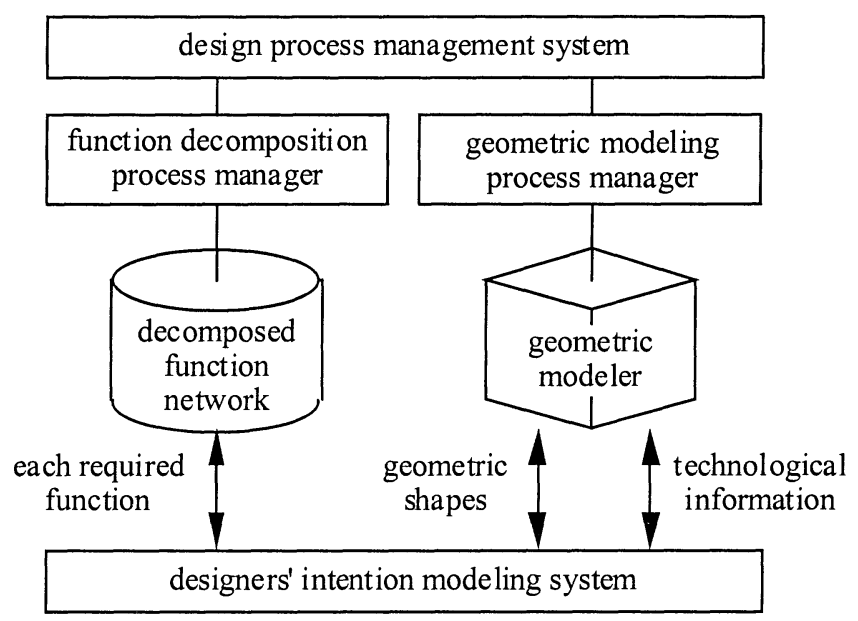

Figure 1 CAD system architecture

The function decomposition process manager generates the decomposed function networks according to the input of designers (Arai, 1998). Nodes in the network indicate the functions, and edges show that the upper node function is decomposed 
into the combination of lower node functions. A chain of nodes shows how the functional requirements are decomposed according to the design progress, which is peculiar to each designer.

Functional decomposition using natural language are available in the developed system, which are analyzed to exact the keywords. CAD system used in cooperative design should also include communication network system to transfer design information among designers.

\section{COMMUNICATION NETWORK SYSTEM}

Communication network system transfers design information among designers. There are several communication control method. Broadcasting is the simplest but inefficient way, and designers have to evaluate and select the information which needs time and pains. Conversation model based communication had proposed to improve the broadcasting shortage (Iwata, 1994). Information senders are required to designate the receivers before starting communication in this case to increase efficiency that requires designers making efforts.

They have to communicate also after making decisions for they may affect on others' design process, however, it is difficult to find whom they should communicate with. The communication network system using the active database is newly developed in this research (Arai, 1998). Active database is used here as a combination of database system and communication control system. Figure 2 shows the architecture of communication network system. It can reduce the designers' effort by realizing the following two functions.

(1) To support designers to designate the communication partners before and during decision making

(2) To start the communication automatically with necessary persons after decision making

These two are realized by preparing the conditions in the database which each designer declares for receiving design information from others.

Functions handled by a designer is send through CAD system to the language analysis system to compare with pre-defined function names, and classified into three. Those are, simple function, set of a function and its decomposition, and set of functions with their periodical relations. These are registered as the trigger condition, and the communication network system is raised when other designers' handling functions match with them.

Input of each designer is also send to the active database where it is compared with functions handled by other designers. When they match, the active database generates the trigger to notify the designer that some other designers have interests in the same functions. When the designer asks to get more detailed information, the system delivers corresponding designers' IDs and the decomposed function 
networks to the requester which must be helpful to start communication to understand with each other.

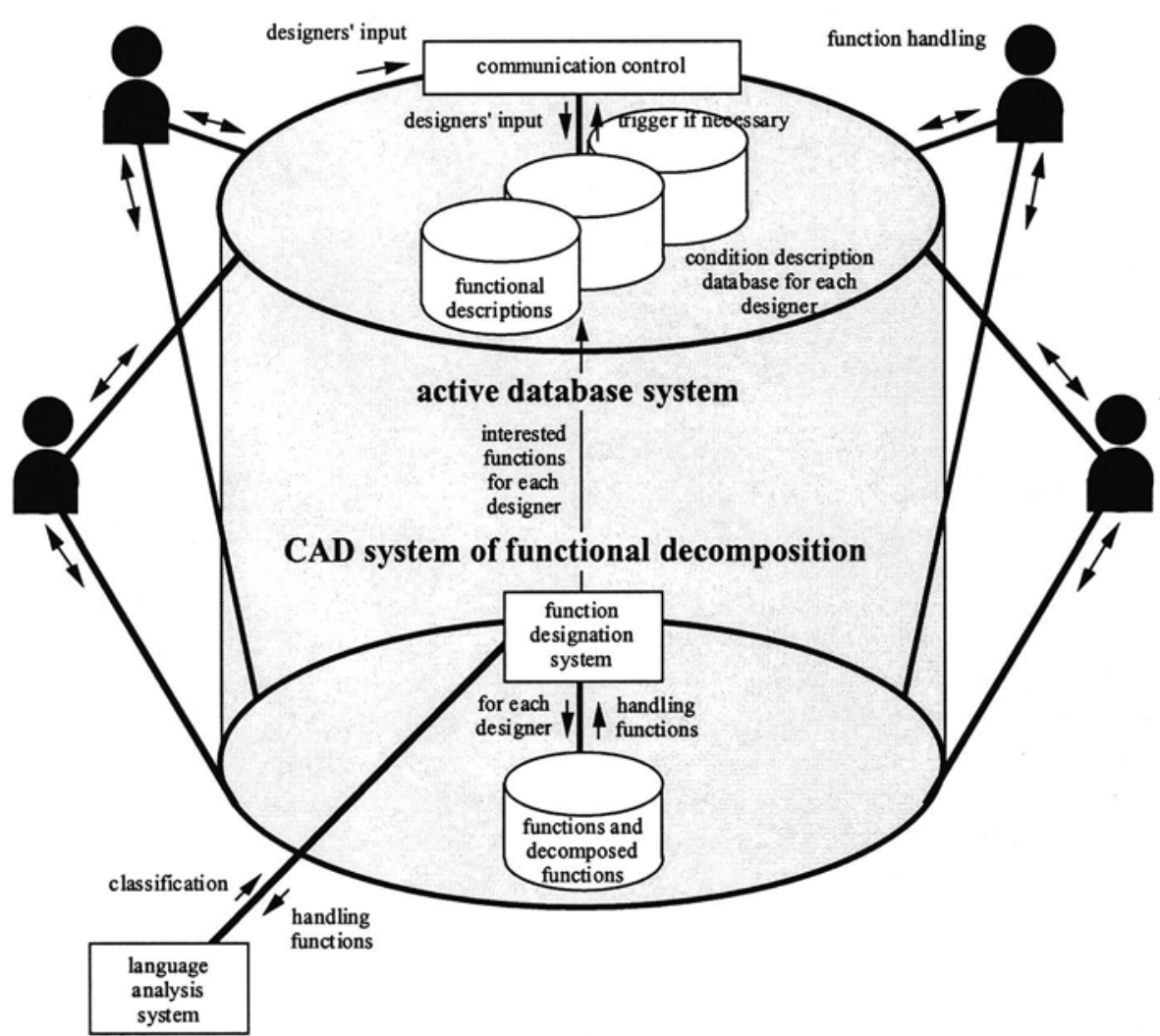

Figure 2 Communication network system architecture

Whenever each designer makes decisions to handle functions of designed objects, the communication network system looks for designers who may be affected on by the decisions automatically with use of the active database system. Designers may use the system actively also to look for the communication partners, for instance, to ask questions by searching the condition database in the active database. The condition database is always renewed by the additional data from the CAD system where the functions are according to the design progress (Sivard, 1993)(Klein, 1994). 


\section{CONDITION DESCRIPTION DATABASE FOR FUNCTIONAL DECOMPOSITION}

There are three kinds of conditions to generate triggers in the active database system. First is simply matching the decomposed function names. When a designer decomposes functions, function names are stored in the condition description database of each designer. The active database also compares each of them with already registered function names of other designers at the same time, and generates the trigger if they match. Figure 3 shows an example that several function names between different design solutions match. The designers may start communication to get valuable information with each other. Function names are detected by the language processing system when designers use the natural language for function description.

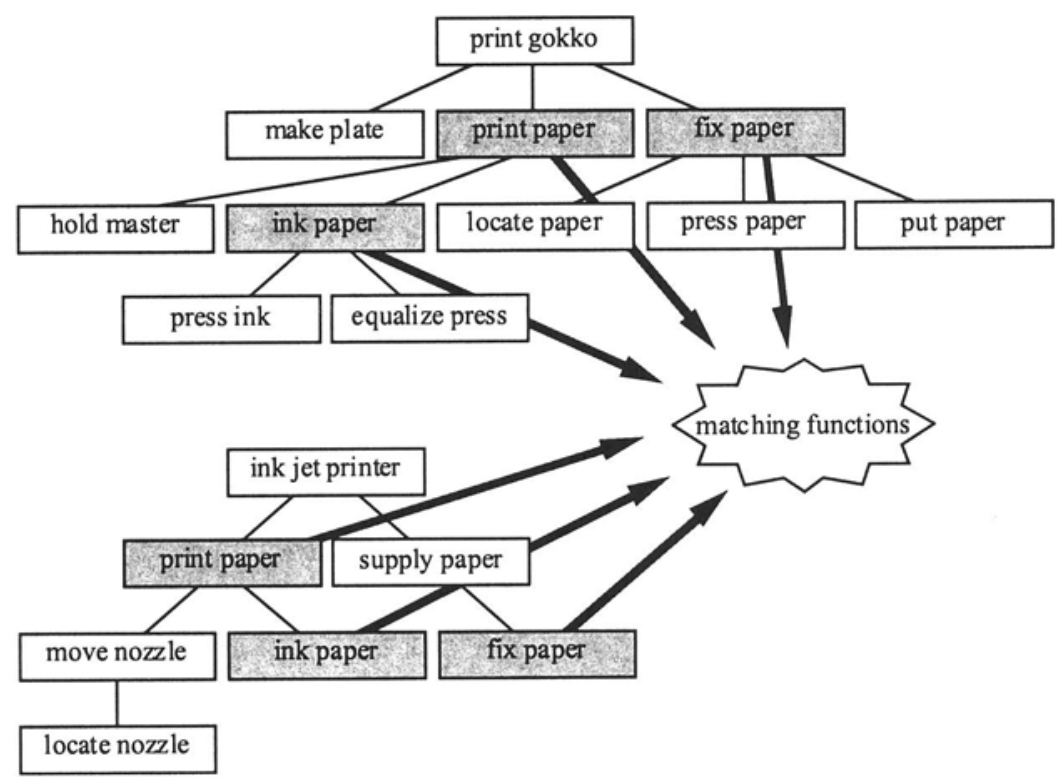

Figure 3 Function matching in different products

Second is the matching of function decomposition network. Different designers may decompose the same function into differently structured network of subfunctions as shown in Figure 4 according to their experiences and so on. The shrinkage of networks which remains only the nodes of matching functions is executed. The active database generates the trigger if the shrunk network structures match as shown in Figure 5.

Third is the matching of periodical conditions among decomposed functions. As shown in Figure 6, decomposed functions have to keep periodical conditions in order to realize the upper level functions. The system compares the periodical 
sequences of decomposed functions referring to Allen's temporal intervals (Allen, 1983) and generates the trigger when they match.

The active database system sends the notification by the trigger to the designers whose decomposed functions etc. match. They are able to communicate for mutual advices.

\section{CONCLUSION}

In concurrent design, designers often don't know communication partners. Especially in the early conceptual design stage, designers of different products sometimes handle the same functions whose mutual advices may be of great values.

Communication network system with using active database system is proposed to support designers to find suitable partners handling the same functions. The notification of communication partners is executed automatically by the conditions when a designer handles the functions to decompose into detailed ones.

There are three types of conditions ; the simple function name matching, the decomposed function network structure matching, and the periodical condition matching among decomposed functions. They can be modified in the near future as the description of design knowledge to refer the solution by functions.
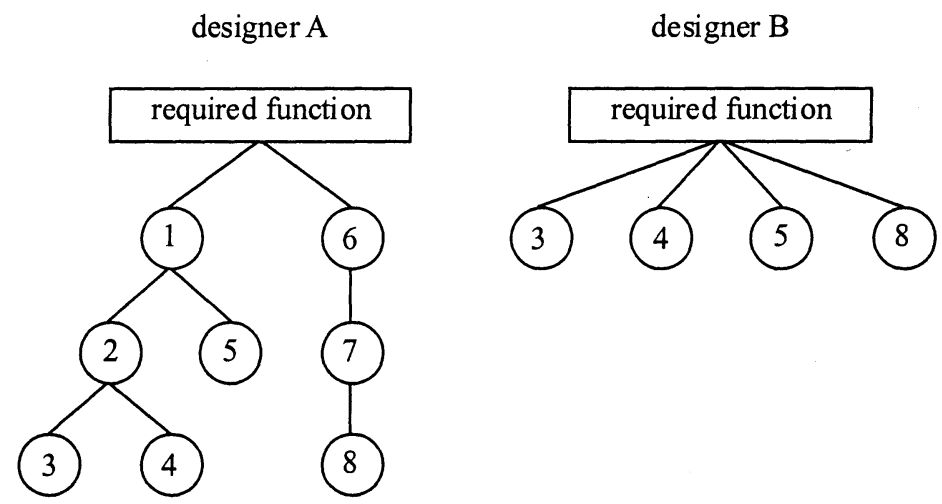

Figure 4 Different network structure of decomposed functions 


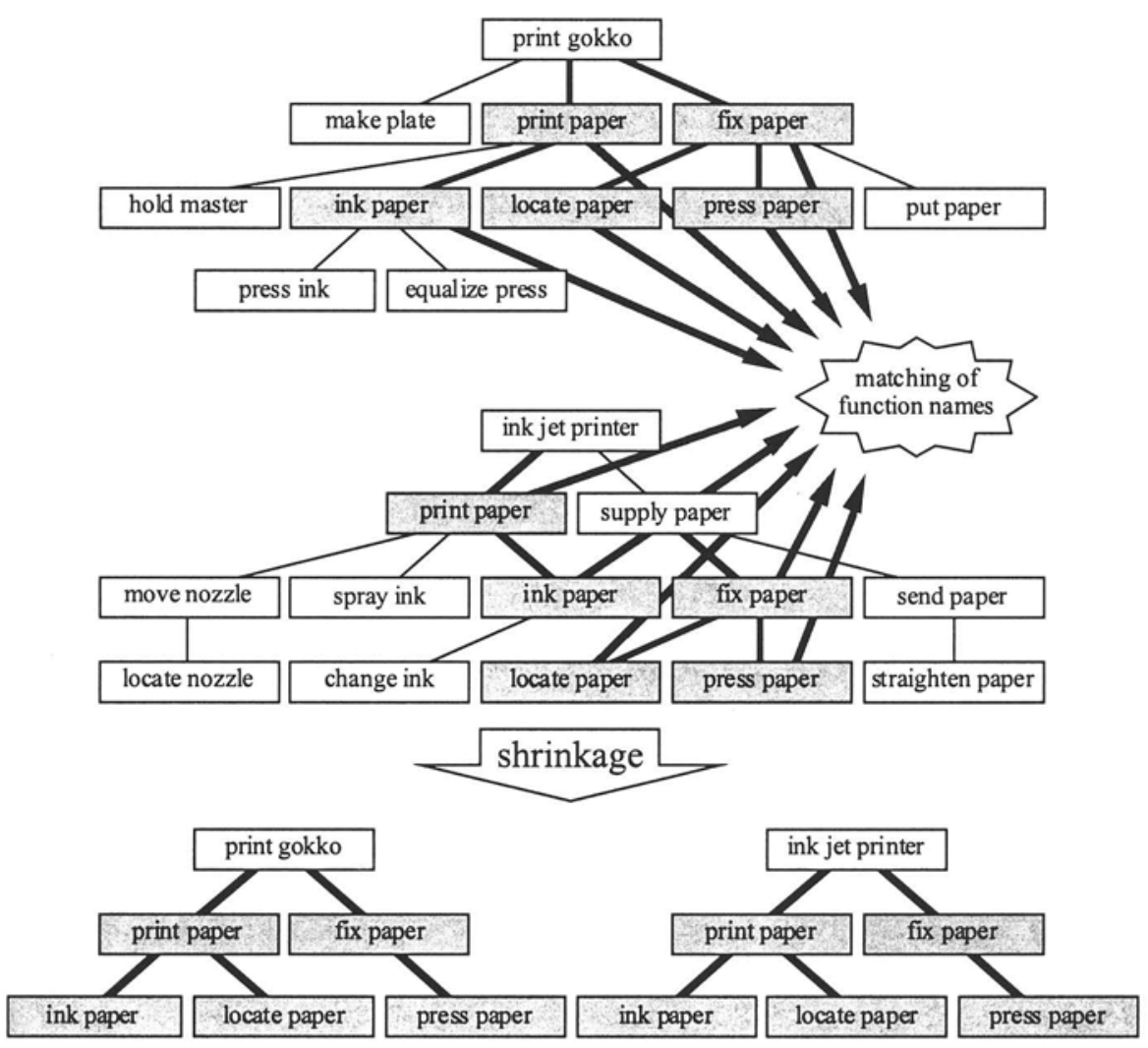

Figure 5 Shrinkage of networks and matching in different products

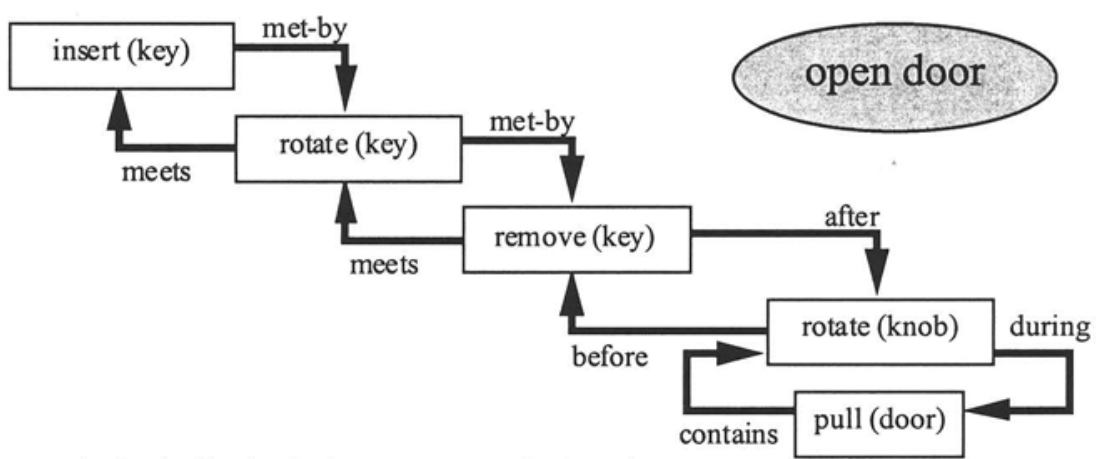

Figure 6 Periodical relations among sub-functions

Note : Sub-functions are described as actions in this case. 


\section{REFERENCES}

Allen, J. (1983) Maintaining knowledge about temporal intervals. communications of ACM, Vol.26, No.11, 832-843.

Arai, E. et al. (1991) Intention Modelling System of Product Designers in Conceptual Design Phase. Manufacturing Systems, Vol.20, No.4, 325-333.

Arai, E. et al. (1998) Designers' Intention Based CAD for Concurrent Engineering. Proc. of 1998 Pacific Conference on Manufacturing, 745-749.

Arai, E. et al. (1998) CAD with use of Designers' Intention. Proc. of The Third IFIP Working Group 5.2 Workshop on Knowledge Intensive CAD, 21-30.

Iwata, K. et al. (1994) Conversation Model and Data Management in HumanCentered Concurrent Engineering. Proc. of IMS'94, 81-86.

Klein, D.A. et al. (1994) A framework for explaining decision-theoretic advice. Artificial Intelligence, Vol.67, No.2, 201-243.

Sivard, G. et al. (1993) Customerbased design with constraint reasoning. Annals of the CIRP, Vol.42, No.1, 139-.

Tomiyama, T. et. al. (1993) A CAD for Functional Design. Annals of the CIRP, vol.42/1, 143-146.

\section{BIOGRAPHIES}

Eiji Arai: Born on January 15 in 1953. In 1980 graduated at Graduated School of Eng. (doctoral course), Univ. of Tokyo. In 1984 became Associate Professor of Shizuoka Univ, in 1992 Associate Professor of Tokyo Metropolitan Univ., in 1995 Professor of Osaka Univ.. Main Research Area includes: (1)Intelligent CAD/CAM Systems, (2)Distributed Production System Architecture, (3)Advanced Production Process.

Keiichi Shirase: Born on December 1 in 1959. In 1984 graduated at Graduated School of Eng. (master course), Kobe Univ. In 1995 became Associate Professor of Kanazawa Univ., in 1996 Associate Professor of Osaka Univ. Main research area includes (1) Autonomous \& Intelligent Machine Tool, (2) Cutting simulation, (3) Intelligent $\mathrm{CAD} / \mathrm{CAM}$ systems.

Hidefumi Wakamatsu: Born on July 27 in 1969. In 1994 graduated at Graduate School of Eng. (master course), Osaka Univ. In 1995 became Research Associate of Osaka Univ.. Main research area includes (1) Manipulation of deformable objects, (2) Planing of robot manipulation, (3) Intelligent CAD/CAM systems. 